\title{
LEI APLICÁVEL A CONTRATOS INTERNACIONAIS NO MERCOSUL
}

Tatyana Scheila Friedrich e Isabela Piacentini de Andrade ${ }^{1}$

\section{RESUMO}

$\mathrm{Na}$ contramão da tendência mundial, os ordenamentos jurídicos dos Estados Partes do Mercosul não admitem a autonomia da vontade na escolha da lei aplicável a contratos internacionais, utilizando-se ainda dos critérios da lei do local de celebração (lex loci celebrationis) ou da lei do local de execução (lex loci executionis) para determinar a lei de regência contratual. Exceção notável e progressista é o recente Acordo sobre Arbitragem Comercial Internacional do Mercosul, o qual admite a autonomia da vontade se as partes elegeram a arbitragem como modo de solução da controvérsias contratuais. Avanço ainda mais promissor seria a incorporação, pelos Estados Partes do Mercosul, da Convenção Interamericana sobre o Direito Aplicável aos Contratos Internacionais oriunda da CIDIP V, segundo a qual as partes têm a liberdade de escolher a lei que regerá o contrato, independentemente do modo de solução da controvérsias eleito.

\section{ABSTRACT}

Against the worldwide tendency, the legislation of the Mercosur State Parties does not admit that the parties to an international contract are free to choose its applicable law; the lex loci celebrationis and lex loci executionis keep being the criteria according to which the applicable law shall be determined. A notable exception to that is the recent Mercosur Agreement for International Commercial Arbitration, which states that the selection of the applicable law is permitted if the parties to the contract decided to submit its disputes to arbitration. An even more welcomed step would be done if Mercosur Parties would adhere to the Inter-American Convention on the Law Applicable to

\footnotetext{
${ }^{1}$ Friedrich: doutora pela UFPR; Andrade: mestranda pela Universidade de Paris II - ambas coordenaram o grupo sobre Contratos Internacionais e Arbitragem no NDI/UFPR em 2005.
}

Revista Brasileira de Direito Internacional, Curitiba, v.2, n.2, jul./dez.2005 
International Contracts, according to which the parties are able to choose the applicable law, irrespectively of the form of contractual dispute settlement.

\section{INTRODUÇÃO}

O contrato internacional é a expressão por excelência do comércio global, é o instrumento que visa a conferir às partes segurança nos negócios entre fronteiras. A intensificação das trocas em âmbito mundial faz do estudo da contratação internacional uma necessidade inadiável.

No contexto de um bloco regional, tal estudo se mostra ainda mais urgente, já que o objetivo de um bloco econômico é exatamente a promoção de trocas comerciais. Faz-se então relevante analisar a situação das normas do Mercosul e seus Estados Partes no tocante a contratos internacionais. Afinal, a existência de um mercado comum pressupõe intenso relacionamento comercial entre países, envolvendo circulação de mercadorias, bens e serviços, relações estas invariavelmente disciplinadas por contratos internacionais.

O presente artigo inicia-se a partir de noções gerais sobre contratos internacionais. Em seguida, examina as legislações internas dos Estados Partes do Mercosul quanto à matéria para, finalmente, analisar o tratamento que o bloco confere ao tema.

\section{NOÇÕES GERAIS SOBRE CONTRATOS INTERNACIONAIS}

Classifica-se um contrato como internacional quando potencialmente incidem sobre ele dois ou mais ordenamentos jurídicos. Não há consenso sobre sua definição, existindo duas correntes a respeito: a primeira, minoritária, denominada corrente econômica, condiciona o caráter internacional do contrato à transposição na fronteira dos Estados dos bens ou de seus valores correspondentes; a segunda, mais abrangente e mais aceita, denominada corrente jurídica, vincula o aspecto internacional à verificação de elemento ou fator de estraneidade, como a nacionalidade diversa das partes, seu domicílio 
em países diferentes, o local de execução em país diferente da celebração, a moeda estrangeira para pagamento, dentre outros.

\title{
Para Irineu STRENGER
}

\begin{abstract}
"são contratos internacionais do comércio todas as manifestações bi ou plurilaterais das partes objetivando relações patrimoniais ou de serviços, cujos elementos sejam vinculantes de dois ou mais sistemas jurídicos extraterritoriais, pela força do domicílio, nacionalidade, sede principal dos negócios, lugar do contrato, lugar de execução, ou qualquer circunstância que exprime um liame indicativo do Direito aplicável."2
\end{abstract}

Não existe, na legislação brasileira, norma que defina expressamente o contrato internacional. Pode-se chegar a uma definição negativa com base no artigo 2 . do Decreto-Lei 857, de 11 de setembro de 1969.

\begin{abstract}
Art. $1^{\circ}$ São nulos de pleno direito os contratos, títulos e quaisquer documentos, bem como as obrigações que exeqüíveis no Brasil, estipulem pagamento em ouro, em moeda estrangeira, ou, por alguma forma, restrinjam ou recusem, nos seus efeitos, o curso legal do cruzeiro.

Art. $2^{\circ}$ Não se aplicam as disposições do artigo anterior:

I - aos contratos e títulos referentes a importação ou exportação de mercadorias;

II - aos contratos de financiamento ou de prestação de garantias relativos às operações de exportação de bens de produção nacional, vendidos a crédito para o exterior;

III - aos contratos de compra e venda de câmbio em geral;

IV - aos empréstimos e quaisquer outras obrigações cujo credor ou devedor seja pessoa residente e domiciliada no exterior, excetuados os contratos de locação de imóveis situados no território nacional;

V - aos contratos que tenham por objeto a cessão, transferência, delegação, assunção ou modificação das obrigações referidas no item anterior, ainda que ambas as partes contratantes sejam pessoas residentes ou domiciliadas no país.

Parágrafo único. Os contratos de locação de bens móveis que estipulem pagamento em moeda estrangeira ficam sujeitos, para sua validade a registro prévio no Banco Central do Brasil.
\end{abstract}

Diante do conceito doutrinário e da disposição legal, pode-se concluir que, quando se estiver diante de um contrato no qual, por exemplo, as partes têm domicílios em países diferentes, ou há trânsito de mercadorias entre fronteiras, ou ainda o contrato foi celebrado num Estado mas sua execução se dará em outro, se está diante de um contrato internacional. Configurada essa hipótese, um ou mais sistemas jurídicos estrangeiros são teoricamente

\footnotetext{
${ }^{2}$ STRENGER, Irineu. Contratos Internacionais de Comércio, $2^{a}$. ed., rev. e ampl. São Paulo: RT, 1992, p. 81.
} 
aplicáveis ao contrato. Durante a execução do avençado ou havendo um litígio entre as partes, demandar-se-á qual a lei aplicável ao caso. Assim como ocorre com as demais hipóteses de conflitos de leis, cabe ao direito internacional privado indicar qual será a lei aplicável à controvérsia obrigacional.

Relata Nadia de ARAÚJO que, inicialmente, os conflitos de normas obrigacionais eram resolvidos pelo critério da lex loci celebrationis. Assim, a lei aplicável ao contrato era aquela do lugar em que ele havia sido celebrado. No século XIX Savigny criticou este critério, qualificando a lei do local de celebração como efêmera e fortuita, e apontando a lei do local de execução da obrigação contratual - lex loci executionis - como a mais adequada. Mas o aumento progressivo do comércio trouxe um novo critério, mais consentâneo com a liberdade de contratar: o da autonomia da vontade das partes na escolha da lei aplicável. Este critério é hoje mundialmente acatado pelas legislações estatais e tratados internacionais. ${ }^{3}$ Entretanto, os países da América Latina, dentre os quais os membros do Mercosul, resistem a essa tendência. Somente através do emprego da arbitragem é que a autonomia tem tido maior acolhida entre nós.

A seguir, passa-se a analisar os ordenamentos nacionais do Brasil, Argentina, Paraguai e Uruguai quanto aos contratos internacionais e a solução aos conflitos de leis dada pelo direito internacional privado de cada país. É válido lembrar que estes países assumiram, através do artigo 1ำ do Tratado de Assunção (o tratado constitutivo do Mercosul), como propósito para o estabelecimento do mercado comum, o "compromisso de harmonizar suas legislações, nas áreas pertinentes, para lograr o fortalecimento do processo de integração". A harmonização legislativa em matéria de contratação internacional é pressuposto para que haja segurança jurídica nas trocas comerciais entre os países do bloco e, ainda, entre estes e terceiros países.

Revista Brasileira de Direito Internacional, Curitiba, v.2, n.2, jul./dez.2005 


\section{ORDENAMENTO JURÍDICO ARGENTINO}

Os conflitos de leis em matéria contratual são disciplinados na Argentina pelos artigos 1205 a 1216 do Código Civil (1869). A Argentina é signatária da Convenção de Montevidéu, que estabelece como regra de conexão em matéria obrigacional a lex loci executionis. Nesta linha, o artigo 1209 do Código argentino determina que se a execução do contrato der-se na Argentina, aplicar-se-á esta lei na sua regência. Caso a execução seja alhures, incidirá a lei do local de celebração do contrato, segundo o artigo 1205 (lex loci celebrationis).

Há alguns juristas argentinos que defendem a aceitação do princípio da autonomia da vontade em solo argentino. GOLDSCHMIDT o fundamenta em norma consuetudinária, originada nos artigos 1143 e 1197 do Código Civil argentino. BOGGIANO baseia a autonomia nos arts. 19 e 31 da Constituição argentina. A jurisprudência, entretanto, é contrária à voz destes doutrinadores, sendo poucos os casos em que admitiu a autonomia das partes na escolha da lei aplicável ao contrato. ${ }^{4}$

A disciplina da arbitragem está no Código Processual Civil e Comercial argentino, não havendo também neste particular aceitação expressa da autonomia da vontade para a escolha da lei aplicável.

As convenções internacionais relacionadas à contratação internacional firmadas pela Argentina foram: o Tratado de Montevidéu (1889/1940), a Convenção de Viena sobre a Compra e Venda Internacional de Mercadorias (1980), a Convenção da ONU sobre o Reconhecimento e Execução de Sentenças e Laudos Arbitrais Estrangeiros (Nova York, 1958), a Convenção Interamericana sobre Arbitragem Comercial Internacional (Panamá, 1975) e a Convenção Interamericana sobre Eficácia Extraterritorial das Sentenças e Laudos Arbitrais Estrangeiros (Montevidéu, 1979).

\footnotetext{
${ }^{3}$ ARAÚJO, Nadia de. Direito internacional privado: teoria e prática brasileira. Rio de Janeiro: Renovar, 2003, p. 314-315.

${ }^{4}$ SOUZA Jr., Lauro da Gama. Os princípios do Unidroit relativos aos contratos comerciais internacionais e sua aplicação nos países do Mercosul. RODAS, Grandino (coord.) Contratos internacionais, 3ª ed. São Paulo: RT, 2002, p. 436-437.
}

Revista Brasileira de Direito Internacional, Curitiba, v.2, n.2, jul./dez.2005 


\section{ORDENAMENTO JURÍDICO URUGUAIO}

Igualmente signatário da Convenção de Montevidéu, o Uruguai adota, no artigo 2399 do seu Código Civil (1868), a lex loci executionis para reger as obrigações quanto à sua existência, natureza, validade e efeitos. Aplica-se, portanto, a lei do local em que a obrigação contratual será cumprida.

A autonomia da vontade não é admitida, havendo interpretação restritiva mesmo à aplicação da autonomia pela via indireta (quando a lei competente a permitir), facultada pelo art. 2403 do Código. Exceção a esta tendência foi decisão do Tribunal de Apelaciones en lo Civil de $6^{\circ}$. Turno (Decisão 81, de 11.06.1997), que admitiu a autonomia pela via indireta. O direito aplicável em questão era o direito turco (lei do local de execução), e a Turquia havia ratificado a Convenção de Bruxelas, escolhida como direito aplicável ao contrato pelas partes. ${ }^{5}$

O Código processual do Uruguai, a exemplo do argentino, não menciona a faculdade das partes elegerem o direito aplicável ao contrato submetido à arbitragem.

No plano internacional, o Uruguai ratificou as seguintes convenções ligadas a contratos internacionais: o Tratado de Montevidéu (1889/1940), a Convenção de Viena sobre a Compra e Venda Internacional de Mercadorias (1980), a Convenção da ONU sobre o Reconhecimento e Execução de Sentenças e Laudos Arbitrais Estrangeiros (Nova York, 1958), a Convenção Interamericana sobre Arbitragem Comercial Internacional (Panamá, 1975) e a Convenção Interamericana sobre Eficácia Extraterritorial das Sentenças e Laudos Arbitrais Estrangeiros (Montevidéu, 1979).

\section{ORDENAMENTO JURÍDICO PARAGUAIO}

O artigo 297 do Código Civil paraguaio indica a lei do Paraguai para obrigações a serem executadas no país. Novamente, pois, trata-se da lex loci

\footnotetext{
${ }^{5}$ SOUZA Jr., Lauro da Gama. Os princípios do Unidroit relativos aos contratos comerciais internacionais e sua aplicação nos países do Mercosul. RODAS, Grandino (coord.) Contratos internacionais, 3ª ed. São Paulo: RT, 2002, p. 438.
}

Revista Brasileira de Direito Internacional, Curitiba, v.2, n.2, jul./dez.2005 
executionis. Também disciplina, no art. 23, que para questões de forma vige a lei do local de celebração (locus regit actum). Alguns juristas paraguaios entrevêem o princípio da autonomia da vontade na escolha da lei aplicável nos artigos 297 e 669 do Código, os quais proclamam a liberdade de contratar, mas a jurisprudência não endossa este entendimento.

A arbitragem é prevista no ordenamento jurídico paraguaio pela própria Constituição, no artigo 248. Em 2002 o Paraguai promulgou uma lei de arbitragem que, baseada na Lei-Modelo da UNCITRAL, dá às partes autonomia para a escolha da lei aplicável (art. 32). Trata-se da Ley 1879, de 24 de março de 2002.

O Paraguai ratificou o Tratado de Montevidéu (1889/ 1940), a Convenção Interamericana sobre Arbitragem Comercial Internacional (Panamá, 1975), a Convenção Interamericana sobre Eficácia Extraterritorial das Sentenças e Laudos Arbitrais Estrangeiros (Montevidéu, 1979), e a Convenção do Banco Mundial (Washington, 1965), referente a solução de litígios sobre investimentos estrangeiros.

\section{ORDENAMENTO JURÍDICO BRASILEIRO}

No Brasil, as regras de direito internacional privado quanto às obrigações estão no artigo $9^{\circ}$. da Lei de Introdução ao Código Civil (LICC, Decreto-lei 4657/42). Para contratos entre presentes, o art $9^{\circ}$., caput, consagra a lei do local de constituição das obrigações como regente (lex loci celebrationis). Já para contratos celebrados entre ausentes, a lei aplicável é a da residência do proponente (art. $9^{\circ}, \S 2^{\circ}$.).

Depreende-se daí que, assim como nos demais países do cone sul, as partes não têm liberdade para escolher a lei aplicável. Na redação anterior à LICC, esta possibilidade era admitida. O artigo 13 da Introdução a Código Civil de 1916 prescrevia:

"Art. 13. Regulará, salvo estipulação em contrário, quanto à substância e aos efeitos das obrigações, a lei do lugar em que fora contraídas."

Revista Brasileira de Direito Internacional, Curitiba, v.2, n.2, jul./dez.2005 
A expressão "salvo estipulação em contrário" levou a doutrina de então a admitir a autonomia da vontade das partes na escolha da lei aplicável. Com a redação de 1942, esta expressão foi suprimida. Algumas vozes ainda sustentaram que, a despeito da supressão, o princípio da autonomia ainda permanecia. Este entendimento, porém, está superado. A doutrina majoritária, dentre os quais Nadia de ARAÚJO e João Grandino RODAS, afirma que, diante do caput taxativo do art. $9^{\circ}$. da LICC, não se pode afirmar a existência da autonomia da vontade para a indicação da norma aplicável no ordenamento brasileiro. ${ }^{6}$ Mas sustenta-se que a autonomia seria aceita de forma indireta. Assim, se a lei do local de celebração do contrato ou a lei do proponente admitirem a autonomia, as partes poderiam estipular a lei aplicável.

Já na esfera arbitral, a recente lei brasileira de arbitragem (9307/96) prescreve:

\footnotetext{
Art. $2^{\circ} \mathrm{A}$ arbitragem poderá ser de direito ou de eqüidade, a critério das partes.

$\S 1^{\circ}$ Poderão as partes escolher, livremente, as regras de direito que serão aplicadas na arbitragem, desde que não haja violação aos bons costumes e à ordem pública.

$\S 2^{\circ}$ Poderão, também, as partes convencionar que a arbitragem se realize com base nos princípios gerais de direito, nos usos e costumes e nas regras internacionais de comércio.
}

Sobre a lei de arbitragem, SOUZA Jr. comenta que "trata-se de verdadeira revolução no direito internacional privado brasileiro, pois a lei confere eficácia à eleição feita pelas partes no contrato, não somente em relação às regras de um dado ordenamento estatal, mas também àquelas que constituem direito não estatal"7.

O Brasil ratificou as seguintes convenções relacionada a contratos internacionais: Código Bustamante (Havana, 1928), Convenção Interamericana sobre Arbitragem Comercial Internacional (Panamá, 1975), Convenção Interamericana sobre a Eficácia Extraterritorial das Sentenças e Laudos

\footnotetext{
${ }^{6}$ RODAS, João Grandino. Elementos de conexão do direito internacional privado brasileiro relativamente às obrigações contratuais. RODAS, João Grandino (coord.) Contratos internacionais, $3^{\mathrm{a}}$. ed. São Paulo: RT, 2002, P. 59.

7 SOUZA Jr., Lauro da Gama. Os princípios do Unidroit relativos aos contratos comerciais internacionais e sua aplicação nos países do Mercosul. RODAS, Grandino (coord.) Contratos internacionais, 3ª ed. São Paulo: RT, 2002, p. 442.
}

Revista Brasileira de Direito Internacional, Curitiba, v.2, n.2, jul./dez.2005 
Arbitrais Estrangeiros (Montevidéu, 1979) e a Convenção da ONU sobre o Reconhecimento e Execução de Sentenças e Laudos Arbitrais Estrangeiros (Nova York, 1958).

\section{NORMATIVAS DO MERCOSUL}

Como se pôde notar nos itens acima, o direito internacional privado dos quatro países integrantes do Mercosul na matéria obrigacional está na contramão da tendência mundial. Os critérios da lex loci celebrationis (Brasil) e lex loci executionis (Argentina, Paraguai e Uruguai) em lugar do critério da autonomia na escolha da lei aplicável podem constituir entrave para a afirmação do Mercosul enquanto bloco que almeja o livre comércio.

Para alavancar o sucesso do bloco é importante que os países do Mercosul estejam alinhados juridicamente quanto à regulamentação dos diversos contratos que travam e travarão entre si, evitando que conflitos de leis impeçam ou dificultem seu desenvolvimento. Nesse sentido, caberia aos países do Mercosul, conforme estabelece $o$ artigo $1^{\circ}$. do Tratado de Assunção, "harmonizar suas legislações", visando ao fortalecimento da integração regional. Não há, entretanto, qualquer norma do Mercosul sobre a lei aplicável a contratos internacionais. Assim esclarece ARAÚJO:

\footnotetext{
"Os contratos internacionais firmados no Mercosul são regidos pelas normas de DIPr de cada país. A situação é insatisfatória, consistindo em barreira jurídica impeditiva da uniformização do DIPr dos contratos no Mercosul. Para o bom funcionamento dos negócios, é preciso unificar essas normas. A inércia dos países-membros pode ter conseqüências desastrosas, a longo prazo, nas relações comerciais do mercado comum, contribuindo para a instabilidade das relações jurídicas". 8
}

Quanto à escolha do foro e à arbitragem a situação é outra. Há previsão normativa regional, apesar de pouco utilizada.

O Protocolo de Buenos Aires tem por objeto regulamentar a questão da jurisdição competente, em virtude de contratos internacionais celebrados entre pessoas físicas ou jurídicas com sede social ou domicílio em diferentes

\footnotetext{
${ }^{8}$ ARAÚJO, Nadia de. Direito internacional privado: teoria e prática brasileira. Rio de Janeiro: Renovar, 2003, p. 335.
}

Revista Brasileira de Direito Internacional, Curitiba, v.2, n.2, jul./dez.2005 
Estados do Mercosul ou quando uma delas esteja nesta condição e, além disso, tenha estabelecido cláusula de eleição de foro em favor de um juiz de um Estado Parte, com conexão razoável.

O âmbito de aplicação do Protocolo limita-se aos contratos de natureza civil ou comercial, excetuando-se as hipóteses previstas no artigo $2^{\circ}$ :

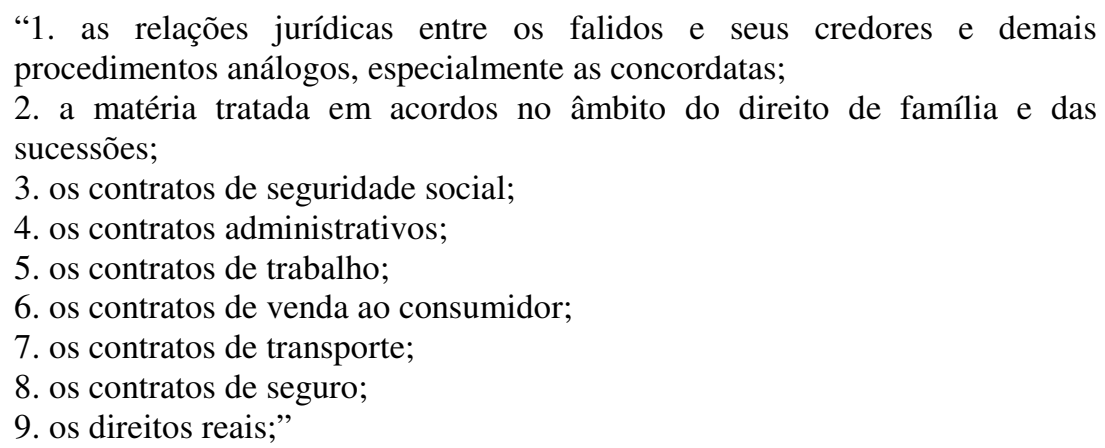

O Protocolo exalta o princípio da autonomia das partes na eleição do foro para dirimir controvérsias que surjam em virtude de um contrato. Assim, estabelece que os tribunais competentes - judiciais ou arbitrais - são aqueles escolhidos livremente pelas partes, seja no momento da celebração do contrato, durante sua vigência ou depois de surgido o litígio. No caso de não existir acordo, o autor pode escolher a jurisdição do lugar de cumprimento do contrato, do domicílio do demandado ou de seu domicílio ou sede social. ${ }^{9}$

Segundo o art. 5ำ, a validade e os efeitos de eleição de foro são regidos pelo direito dos Estados-Partes que teriam jurisdição de conformidade com o estabelecido nesse Protocolo, aplicando-se sempre o direito mais favorável à validade do acordo.

O Protocolo admite, também, a escolha de tribunais arbitrais.

Sobre a arbitragem, entretanto, entrou em vigor recentemente o Acordo sobre Arbitragem Comercial Internacional do Mercosul, representando considerável avanço para o bloco. O Acordo uniformiza a aplicação da arbitragem entre os Estados Partes, tendo sido elaborado com base na LeiModelo da UNCITRAL, seguindo portanto o padrão mundial. Através do artigo

\footnotetext{
${ }^{9}$ O Protocolo, através de normas qualificadoras, faz a definição e esclarecimento de cada uma dessas hipóteses, nos artigos $8^{\circ}$ a 12.
}

Revista Brasileira de Direito Internacional, Curitiba, v.2, n.2, jul./dez.2005 
10 do Acordo, se quis consagrar a autonomia da vontade em matéria de escolha do direito aplicável:

\footnotetext{
"Artigo 10

As partes poderão eleger o direito que se aplicará para solucionar a controvérsia com base no direito internacional privado e seus princípios, assim como no direito de comércio internacional. Se as partes nada dispuserem sobre esta matéria, os árbitros decidirão conforme as mesmas fontes."
}

O Brasil, entretanto, entendeu que este artigo 10 limitava o âmbito de aplicação do art. $2^{\circ}$. da lei 9307/96 supracitado, ratificando o Acordo através do Decreto 4719/2003 com a seguinte reserva:

\begin{abstract}
Art. 1-O Acordo sobre Arbitragem Comercial Internacional do Mercosul, concluído em Buenos Aires, em 23 de julho de 1998, apenso por cópia ao presente Decreto, será executado e cumprido como nele se contém, ressalvado seu art. 10, que deve ser interpretado no sentido de permitir às partes escolherem, livremente, as regras de direito aplicáveis à matéria a que se refere o dispositivo em questão, respeitada a ordem pública internacional.
\end{abstract}

\title{
8 CONVENÇÃO SOBRE O DIREITO APLICÁVEL AOS CONTRATOS INTERNACIONAIS (CIDIP V, México, 1994)
}

Em 1994, no México, países integrantes da OEA (Organização dos Estados Americanos) reuniram-se na $5^{\text {a }}$. Conferência Especializada Interamericana sobre Direito Internacional Privado (CIDIP V) convocada pela Assembléia Geral da OEA.

Uma das convenções concebidas neste encontro foi a Convenção sobre o Direito Aplicável aos Contratos Internacionais. Trata-se de diploma moderno que permite a eleição pelas partes, expressa ou tácita, do direito aplicável ao contrato (art. $7^{\circ}$.). Caso as partes não tenham exercido a faculdade de escolha, a lei aplicável será aquela que possua vínculos mais estreitos com o contrato (art. $9^{\circ}$.).

A Convenção já está em vigor desde 1996, porém apenas para México e Venezuela. Brasil, Bolívia e Uruguai também assinaram a convenção, porém ainda não a ratificaram.

Revista Brasileira de Direito Internacional, Curitiba, v.2, n.2, jul./dez.2005 
A relação entre a produção normativa no âmbito da OEA e aquela realizada pelos fenômenos de integração latino-americano é bastante controversa. A doutrina encontra-se dividida e muitos autores entendem que tais regras deveriam ser utilizadas no âmbito do Mercosul, sem necessidade de elaboração e internalização de novas normas, através de acordos regionais específicos - o que traria maior agilidade na regulamentação dessa matéria.

\footnotetext{
"Considerando que a maioria das CIDIPs já foi assinada pelos quatro Estados-partes do Mercosul (...) teremos normas harmonizadas de conflito de leis, para o conjunto do Mercosul. Em prazo muito curto podemos ter Direito Internacional Privado convencional em vigor em todas as matérias reguladas pelas CIDIPs, vinculando todos os signatários de tais Convenções, mas com desdobramentos particularmente interessantes, nas relações intra-Mercosul. A listagem temática das CIDIPs compreende quatro grandes áreas: as regras de Direito Internacional Privado, o Direito Comercial e arbitragem, o Direito Processual Civil e o Direito de Família". ${ }^{10}$
}

Por outro lado, há os que defendem a celebração de tratados limitados ao âmbito do Mercosul, de forma a criar regras próprias de acordo com a realidade das questões de Direito Internacional Privado da região.

\begin{abstract}
"Como puede apreciarse, los beneficios que se pretenden a partir de elaborar normativa cooperante adecuada resultan óbvios ya que desde la faz operativa, las posibilidades de incrementar las relaciones comerciales intrazona se amplían y com ello se propician las inversiones a que de lugar tal incremento. La principal consecuencia redundará em el mayor desarrollo de los Estados que deciden apostar a favor del esquema. La necesidad de abordar estos temas cuando los mismos ya habian sido objeto de regulación em otros instrumentos normativos americanos cobra sentido em tanto se diferencien los principio y los objetivos de ambas dimensiones." ${ }^{11}$
\end{abstract}

Diante da lacuna hoje existente no Mercosul sobre a matéria, a incorporação da Convenção Interamericana pelos Estados Partes representaria, em nossa opinião, enorme contribuição à segurança jurídica do mercado comum, além de avanço significativo rumo à tendência mundial sobre autonomia da vontade. Urge que a comunidade jurídica, cada vez mais instada

10 CASELLA, Paulo Borba. Internacionalização do Direito e Impacto da harmonização legislativa no Mercosul - o desafio para os profissionais da área jurídica. Ciência Jurídica. Notas e Comentários. Ano X, vol. 69, maio junho, 1996. p.441.

${ }^{11}$ KLORM, Adriana Dreyzin de. El Protocolo sobre Cooperación y Asistencia Jurisdiccional em Matéria Civil, Comercial, Laboral y Administrativa con particular referencia al reconocimiento y ejecución de sentencias y laudos arbitrales. Revista de Derecho del Mercosur. Ano 4, no. 2, abril 2000. Buenos Aires : La Ley e Síntese Editora. p. 93.

Revista Brasileira de Direito Internacional, Curitiba, v.2, n.2, jul./dez.2005 
a voltar suas atenções para o cenário internacional, preocupe-se e mobilize-se em prol deste avanço em busca de uma maior inserção do Mercosul no cenário internacional.

\section{REFERÊNCIAS}

ARAÚJO, Nadia de. Direito internacional privado: teoria e prática brasileira. Rio de Janeiro: Renovar, 2003.

CASELLA, Paulo Borba. Internacionalização do Direito e Impacto da harmonização legislativa no Mercosul - o desafio para os profissionais da área jurídica. Ciência Jurídica. Notas e Comentários. Ano X, vol. 69, maio junho, 1996. p.441.

KLORM, Adriana Dreyzin de. El Protocolo sobre Cooperación y Asistencia Jurisdiccional em Matéria Civil, Comercial, Laboral y Administrativa con particular referencia al reconocimiento y ejecución de sentencias y laudos arbitrales. Revista de Derecho del Mercosur. Ano 4, no. 2, abril 2000. Buenos Aires : La Ley e Síntese Editora. p. 93.

RODAS, João Grandino. Elementos de conexão do direito internacional privado brasileiro relativamente às obrigações contratuais. RODAS, João Grandino (coord.) Contratos internacionais, $3^{\mathrm{a}}$. ed. São Paulo: RT, 2002.

SOUZA Jr., Lauro da Gama. Os princípios do Unidroit relativos aos contratos comerciais internacionais e sua aplicação nos países do Mercosul. RODAS, Grandino (coord.) Contratos internacionais, 3a . ed. São Paulo: RT, 2002.

STRENGER, Irineu. Contratos Internacionais de Comércio, $2^{\mathrm{a}}$. ed., rev. e ampl. São Paulo: RT, 1992.

Revista Brasileira de Direito Internacional, Curitiba, v.2, n.2, jul./dez.2005 